Derecho \& Realidad

Núm. 24 • II semestre de 2014

Facultad de Derecho y Ciencias Sociales, UPTC

ISSN: 1692-3936

\title{
Derechos humanos: su presencia en las constituciones colombianas. Parte Ji del análisis de contenido de los textos correspondientes a las Constituciones de 1886 × 1991
}

Human rights: their presence in Colombian Constitutions. Part I About the analysis of content of the texts corresponding to the Constitutions of 1886 and 1991

Miguel Ángel Sierra Baena, Alonso Sierra Londoño, Óscar de Jesús Zapata Ocampo*

Resumen

En el marco del proyecto de investigación "Interacción con minorías socioculturales (M.S.C) en el contexto universitario tradicional de Medellín (1980-2008): lectura desde N historias de vida”, patrocinado por el Instituto Colombiano para el Desarrollo de la Ciencia y la Tecnología "Francisco José de Caldas" -COLCIENCIAS-, se estudiaron las principales Constituciones colombianas, promulgadas entre 1821 y el presente, y sus reformas. Se concentró el análisis en cuatro de esas Constituciones y se eligieron, como corpus de investigación, las correspondientes a 1886 y 1991.

* Profesores asociados de la Universidad Nacional de Colombia, sede Medellín, Facultad Nacional de Minas, integrantes de GRITE -Grupo de Reflexión e Investigación sobre Técnicas Educativas-. Correo electrónico: masierra13@gmail.com, jasierra@unal.edu.co, ozom@epm.net.co 
Más que dedicarse al proceso de análisis del contenido de los textos constitucionales y con el fin de motivar el debate posterior, esta ponencia hace énfasis en las reflexiones iniciales (interpretaciones, sentidos, inferencias y contextos) de los autores sobre la presencia y tratamiento de los derechos humanos -primera, segunda y tercera generaciones, especialmente aquellos que pueden favorecer a las minorías socioculturales- en estas dos Constituciones de nuestro país.

\title{
Palabras clave
}

Derechos humanos, legislación colombiana, minorías socioculturales.

\begin{abstract}
As part of the research project "Interaction With Sociocultural Minorities (MSC) in the University Traditional Context of Medellin (1980-2008): Reading from $N$ Life Stories, sponsored by the Colombian Institute for the Development of Science and Technology Francisco José de Caldas" COLCIENCIAS- major Colombian Constitutions, enacted between 1821 and the present, and their reforms were studied. The analysis focused on four of these Constitutions and they were chosen as research corpus, corresponding to 1886 and 1991.

Rather than engage in the process of analyzing the content of the constitutional text and to motivate the subsequent discussion, this paper emphasizes the early reflections (interpretations, meanings, inferences, and contexts) of authors in the presence and processing of human rights -of first, second and third generations, especially those who may favor socio-cultural minoritiesin these two Constitutions of our country.
\end{abstract}

\section{Keywords}

Human rights, Colombian legislation, cultural minorities. 


\section{Introducción}

Con la asesoría del doctor Néstor Cardoso Erlam, profesor del Doctorado en Ciencias de la Educación de RUDECOLOMBIA, y antes de llegar a las reflexiones iniciales que se detallan en las páginas siguientes, se efectuó, en resumen:

Búsqueda en bibliotecas de Tunja, Bogotá y Medellín, así como en Internet, de los temas: derechos humanos, Constituciones colombianas, legislación colombiana y derechos humanos. Lectura detallada y comparación de las Constituciones de 1821, 1863,1886 y 1991.

Elección de un corpus de fuentes secundarias configurado por dos Constituciones 1886 y 1991- que consideramos como principales en la historia de Colombia por su vigencia $\mathrm{y}$, sobre todo, por los cambios sociales, políticos y religiosos que introdujeron en el país, especialmente por su importancia para el tratamiento de los derechos humanos. Trabajo teórico correspondiente a formulación de hipótesis y objetivos, determinación de categorías.

Aprovechamiento del material -selección y codificación, en cada Constitución del corpus, de los artículos que se refieran a derechos humanos; escritura de sendas fichas de análisis para los artículos seleccionados; agrupación de fichas según tipo de derecho (primera, segunda o tercera generación,); conteo, en cada Constitución, de los derechos de cada generación; determinación de frecuencias; elaboración de tablas y figuras.

Redacción de las reflexiones iniciales -interpretaciones, sentidos, inferencias y contextos-.

Reflexiones iniciales -interpretaciones, sentido, inferencias, contextos (1886, 1991, hoy)-

"La regeneración de Núñez amenazaba a todos los liberales radicales; las medidas para acabar con el caos del país no se restringían a la mera palabra, también existía la represión armada..."

J. C. González (p. 162-163).

"Todo en él tuvo la densa oscuridad del abismo".

J.M. Vargas Vila

\footnotetext{
Aquí, Vargas Vila se refiere al presidente Rafael Núñez.
} 
1. En la Figura 1 se ve el aumento difícil con el tiempo (lapso de más de un siglo), de la base de derechos humanos presentes en las dos Constituciones del corpus. De aquí puede inferirse el conservadurismo dominante en el país, su legislación y sus instituciones, desde 1886. Debe destacarse el papel que ha desempeñado la Iglesia católica en esta situación y los privilegios que siempre ha defendido; privilegios que son claros en la Constitución de 1886 (artículos 53, 54, 55 y 56), donde conforman el Título IV "De las relaciones entre la Iglesia y el Estado". De ahí podría desprenderse que con estos privilegios y esta Constitución se terminó la disputa que, a partir de la Constitución de Rionegro (1863), presenciaba y sufría el país. Tal disputa entre el Estado colombiano y la Iglesia católica fue dirimida definitivamente en 1887 -con la firma de un concordato- por el presidente colombiano Rafael Wenceslao Núñez Moledo quien, invocando la necesidad de paz religiosa para Colombia y obteniendo el beneplácito clerical para su unión con Soledad Román Polanco y Ripoll, cedió a las pretensiones económicas y de dominio total de la educación colombiana por parte de la Santa Sede. Por la época de la firma del Concordato, la investigación científica y la educación en Colombia quedaron en una situación que puede verse reflejada en la afirmación siguiente: “...se prohibió la lectura de autores impíos como Darwin, Bentham, Spencer y Tracy..." (Banco de la República, s.f.).

2. A pesar de que la Constitución de 1991, en su artículo 380, derogó la de 1886, los privilegios de la Iglesia católica hoy siguen incólumes. Al respecto ver, por ejemplo, la tranquilidad -y forma evasiva al tocarse el tema de impuestos ${ }^{2}$ - con la que se expresa monseñor Luis Augusto Castro, presidente de la Asamblea Plenaria del Episcopado Colombiano (Garibello, 2006).

La situación podría explicarse en 1886, en 1991 y aún hoy, si consideramos la forma como los "dogmas de fe" católicos son "impuestos" desde la niñez muy temprana, los correspondientes refuerzos periódicos ("sacramentos" del bautismo, confirmación, confesión, comunión, matrimonio), la condena personal y social ante "faltas" contra Dios y sus ministros ("excomunión", que fácilmente equivaldría a un destierro físico), la activa, inmensa y multiforme "sociabilidad católica" -otro tipo de refuerzo para los dogmas y su puesta en práctica (expresada dicha sociabilidad mediante grupos de oración, catequesis, beneficencia, asistencia a desarraigados, entidades educativas y de salud, etcétera)- que penetran conciencias, cuerpos y "almas". Remata este proceso la promesa de la "vida eterna", "salvación del alma", gozos postmortem a condición de una vida terrenal llena de sacrificios (y, obviamente, de obediencia a los preceptos y dogma católicos).

2 Gravámenes de los cuales liberó la Constitución de Núñez a la Iglesia católica. 
3. Del análisis de las dos Constituciones del corpus puede derivarse una relación entre la presencia de los "derechos" de la Iglesia y la presencia de los derechos humanos: a mayor presencia de los primeros, menor importancia de los segundos y viceversa. Esto se constataría, al menos, en el papel: 6 artículos $(38,41,53,54$, $55,56)$ que hablan expresamente en la Constitución de 1886, de "derechos" de la Iglesia católica ${ }^{3}$, contra ninguno específico para ella en la Constitución de 1991.

Lo aquí expuesto podría "advertirse" desde el preámbulo de cada Constitución: mientras la de 1886 se decreta "En nombre de Dios, fuente de toda autoridad..." (Pombo \& Guerra, 1951, p. 207), en la de 1991 es "El Pueblo de Colombia...invocando la protección de Dios...[el que]...decreta, sanciona y promulga... "[la constitución]" (Constitución, 2006, p. 7). Esa "entrega total" a Dios (en cuyo nombre dice actuar la Iglesia católica) por parte de la Constitución de 1886 nos dice mucho... Razón tienen al afirmar que “...un preámbulo presenta un contenido ideológico, que refleja el momento histórico que vive un estado y la ideología que, por lo menos, imaginariamente aparece como dominante. " [y que] "A partir de los preámbulos puede establecerse el contexto histórico que vivía una nación y responder de acuerdo a su contenido interrogantes tales como: cuál era el tipo de legitimidad de la época, quién la detentaba... cuáles eran los problemas álgidos que enfrentaba la nación, si se trataba de un estado confesional o laico, los territorios que la integraban, quién ejercía el poder constituyente, etc. " (Pág. web docencia.udea.)

4. Obviamente que, en el anterior orden de ideas, al leer el preámbulo de la Constitución de 1886 es posible descubrir que el Estado colombiano era (?) totalmente confesional, la legitimidad era detentada por el presidente -Núñez, a pesar de haber terminado su gobierno en el momento de la promulgación, era el "poder detrás del trono"-, los estados (en conflicto constante, conflicto en los cuales participaba activamente la Iglesia católica) eran Antioquia, Bolívar, Boyacá, Cauca, Cundinamarca, Magdalena, Panamá, Santander y Tolima; y en sendos delegatarios -escogidos entre los amigos más cercanos de Núñez- de estos estados descansaba el poder constituyente. Primaba el afán de “...afianzar la unidad nacional y asegurar los bienes de justicia, la libertad y la paz..." (Preámbulo de la Constitución de 1886). (El resaltado no es del original). En fin, esta Constitución parece, desde su preámbulo, escrita para mantener el "statu quo".

Cuando se discutió y definió la Constitución de 1991, los aires habían cambiado: los constituyentes se eligieron popularmente de entre una diversidad de grupos

3 En este trabajo consideraremos que sólo los artículos 38 y 41 tendrían "algo de derechos", los cuatro restantes son, claramente, privilegios. 
políticos, étnicos, sociales, la época parecía corresponder a aperturas ideológicas, económicas, donde primaría el interés por la "convivencia, el trabajo, la justicia, la igualdad, el conocimiento, la libertad, la paz (...) dentro de un marco jurídico, democrático y participativo..." (preámbulo de la Constitución de 1991). Quizás por esto la presencia omnipotente de la Iglesia católica no es tan palmaria (solo se invoca, en el preámbulo, “... la protección de Dios”).

5. Como muestra fehaciente de la escasa preocupación de la Constitución de 1886 por los derechos humanos, está su artículo 121, famoso porque fue utilizado para "gobernar" por casi todos los veinticuatro presidentes que -desde Núñez hasta Barco Vargas- fungieron como tales bajo esta Constitución. El 121 dista mucho, debido a la enorme capacidad demostrada por este para hollar los derechos humanos, del que podría ser, según algunos -ver, por ejemplo Banco de la República (1991), el equivalente en la Constitución de 1991 (el artículo 212 que se aplica solamente en caso de "guerra exterior").

6. Después de analizar varias de las principales Constituciones de Colombia, podemos concluir que la menos progresista, con respecto a las posibilidades que dio a los derechos humanos, es la de 1886 -seguida de la de 1821- y la más liberal sería la de 1863, seguida de la de 1991. Leyendo un poco más acerca del continuo reacción-liberalidad que encierra cada una de estas Constituciones, puede concluirse que a Colombia -no solo para el desarrollo y aplicación de los derechos humanosle han convenido más las Constituciones de corte liberal. Al respecto, una fuente del presente dice, comparando muy directamente la Constitución más retrograda y la más liberal -de las cuatro que acabamos de mencionar en este numeral-: "Este régimen [se refiere al correspondiente a los Estados Unidos de Colombia, instaurado por la Constitución de 1863] duró hasta 1886, y durante su vigencia, el país acusó un progreso en todos los órdenes, y firmó un contrato (1878) para la apertura del canal de Panamá" (García-Pelayo, 1984, p. 1209). Poco duró "tanta belleza”. Siguiendo con García-Pelayo y Gross, "En 1886, el presidente Rafael Núñez, con el apoyo del Partido Conservador, abolió el régimen federal, y volvió a la forma centralista y unitaria. El país fue denominado República de Colombia, que ha conservado hasta nuestros días. Este periodo se ha llamado la Regeneración, y durante... [él]..., se produjo la separación de Panamá (1903), en la cual tuvo influencia decisiva el apoyo de los norteamericanos a los separatistas panameños." (García-Pelayo, 1984).

Núñez no solo contó con el apoyo -resaltado en el párrafo anterior- del Partido Conservador. Margarita Garrido, profesora de la Universidad del Valle, nos dice que "La Regeneración fue el nombre político de un proyecto nacional-estatal abanderado por Rafael Núñez y respaldado por la Iglesia, el ejército conservador y el partido nacional. 'Regeneración administrativa fundamental o catástrofe' fue 
la frase con que se planteó la disyuntiva entre el orden y el caos... En el discurso autoritario regenerador confluyen cómodamente los elementos de jerarquía y orden de la tradición española y católica y el elemento de autoridad de raíz liberal ilustrada (...) De lo colonial se rescata lo que se señala como la 'profunda esencia católica de la sociedad' la cual lleva a la obediencia y al respeto de las instituciones sociales, de las autoridades y de la ley; de lo republicano se rescata la gesta patriótica de la independencia y los héroes como fundadores de la República." (Garrido, 1995, p. 68-69). Esta mezcla de características coloniales y republicanas se ve reflejada en el sector educativo de 1886 -y, por ende, en el derecho a la libertad de enseñanza, aprendizaje, investigación y cátedra-, en la llamada por Núñez "Paz Científica", "...mezcla escolástico-positivista... que considera que debe fomentarse la ciencia pero bajo la supremacía y vigilancia de la Iglesia." (Londoño, 1972, p. 39)-.

Es decir, que con la Regeneración -afianzada en la Constitución de 1886-, y sus "mezclas", se torpedearon los propósitos anticlericales, liberalizadores y progresistas del ideario ilustrado -y, por ende, del positivismo-, propósitos que sustentaron la Constitución de 1863, y se suspendió el desarrollo económico, social y cultural que caracterizó a los Estados Unidos de Colombia. Así, según nuestra opinión, la Constitución de 1886 y las leyes posteriores basadas en ella -por ejemplo las leyes 153 y 61 (Ley de los Caballos) de 1888- se constituyeron en un verdadero lastre para la historia del país, especialmente para el desarrollo de los derechos humanos y del sector educativo. Tal rémora parece que acompañó a Colombia hasta 1991; en ese año, y gracias a la nueva Constitución, algo se recuperó, con respecto a las garantías individuales y sociales existentes en la época de los Estados Unidos de Colombia.

7. Lo expuesto en las líneas últimas nos parece importante para los colombianos de hoy, pues muchos rasgos de los gobiernos de Núñez son anhelados por el de la "Paz Democrática". ¿Será que con este retrocedemos tanto como con aquellos? ¿Y durante tantísimo tiempo? Otras coincidencias entre el gobierno de la "Paz Científica" y el de la "Paz Democrática" pueden encontrarse en el texto mencionado de la profesora Garrido; por ejemplo, nos dice que "De nuevo en ese final de siglo XIX se sigue buscando por encima de todo el reconocimiento internacional. Núñez insistirá frecuentemente en sus artículos en la necesidad de entrar en el concierto de naciones. " (Garrido, 1995, p. 70). (El resaltado no es del original). Igualmente, en la Colombia de hoy, en sus principales dirigentes políticos y clericales, con el pretexto de insertarnos "en el concierto de naciones", prevalece, idealizando el pasado, el ansia por el culto acrítico y vergonzoso a la tecnología y cultura de las grandes potencias mundiales (todavía en Europa y en Norte América). Hoy se intenta copiar dichas tecnologías y culturas, sin digerirlas, a la zaga del resto de países latinoamericanos, y despreciando los propios esfuerzos científicos y nuestras 
tradiciones, hollando -internamente- el derecho al trabajo en condiciones dignas, a la educación autóctona, etcétera. No importa que en el afán por "insertarnos", se niegue la heterogeneidad y riqueza, étnica y cultural, de Colombia, ni que se insista en caer en las tradicionales barreras intelectuales (dogmatismo, intolerancia, veleidad, imitación de doctrinas, denigración de lo propio, ostentación de prestigio, simulación, practicismo deformativo, indiferencia) de nuestro país. No importa que se nos quite otra Panamá. Se olvida así la imperiosa necesidad de buscar, en todas las esferas, caminos autóctonos para aprehender lo universal. En este orden de ideas cabe reflexionar un poco sobre el papel de Colombia en el denominado Tratado de Libre Comercio que algunos se desvelan por firmar con Estados Unidos (El Tiempo, 2006a; 2006b), algo sobre lo cual ya hemos escrito recientemente (Sierra, Zapata \& Sierra, 2007).

8. Con respecto al derecho primordial de la educación y a su aplicación en Colombia, podría encontrarse en la mezcla "escolástico-positivista", o "colonialrepublicana”, que ha regido al país desde 1886 y de la cual hablamos atrás, un argumento más para reforzar nuestra tesis de que la educación impartida en las instituciones de la educación superior colombiana conserva hoy muchas de las características correspondientes a las universidades españolas y de sus colonias en el Nuevo Mundo, en las postrimerías del siglo XVIII: “...predominio de un sistema libresco, memorista, cuyo espíritu estrecho no era propicio para estimular la investigación científica, congelando el saber en simples fórmulas tradicionales...[y] ...el impacto de la Ilustración no fue igual en todas ellas, varias continuaron viviendo dentro de los mismos esquemas hasta bien entrado el siglo XIX y aún después de la Independencia, por lo que fueron 'coloniales fuera de la Colonia'”. (Sierra, Zapata \& Sierra, 2007, p. 21). Consideramos que estas características de las universidades de los siglos XVIII y XIX se cumplen, aún hoy, en muchas universidades paradigmas de la educación superior colombiana y que propuestas para reformas "académicoadministrativas" que dicen querer enderezar la situación, la agravan, por el contrario. Además, características "deseables" de la universidad del siglo XVIII, tales como su concepción unitaria, el cogobierno y la autonomía -en cierne- universitaria, no se dan, ahora, en nuestra educación superior. Pensamos que amplios sectores universitarios colombianos son "coloniales fuera de la Colonia"; es más, nos atrevemos a decir que conservan demasiados rasgos del etos universitario medieval y que las medidas gubernamentales propuestas y aplicadas para el Sector van en contravía de las características "deseables" mencionadas (como ejemplo prestar atención a la crisis actual de la Universidad Nacional de Colombia, crisis profundamente relacionada con las últimas "Reformas académicas y administrativas" -conectadas con medidas económicas disfrazadas de "planes de desarrollo"- que allí desea imponer el actual gobierno del país). 
9. En las figuras 2 y 3 , se nota como aumenta el número de artículos sobre los derechos humanos -por tipo y con respecto a la de 1886-, en la Constitución de 1991. Los mayores aumentos corresponden a los derechos de segunda y tercera generación -quizás impensables en el contexto pacato y constreñido de 1886 y años siguientes-. Se requirieron más de cien años para que -al menos en el papel- Colombia avanzara en el ofrecimiento de garantías constitucionales para los derechos humanos, particularmente los correspondientes a las minorías: como ejemplo, gracias a la Constitución de 1991 y en desarrollo de su artículo 176, sobre derechos Tipo 1, se expidió la ley 649 de 2001 (nótese, 10 años después de promulgada la Constitución) que busca "...asegurar la participación en la Cámara de Representantes de los grupos étnicos, las minorías políticas y los colombianos residentes en el exterior. " (Constitución Política, 2006, p. 158). Asimismo, el ambiente más propicio a la consideración de los derechos humanos, creado por la Constitución de 1991, permitió promulgar leyes para intentar proteger los derechos de una de las minorías sociales más importantes hoy: los desplazados colombianos.

10. Al amparo de la Constitución del 91 se ha legislado y aplicado justicia acerca de los derechos de las minorías mencionadas y de otras: leyes 70 de $1993^{4}, 387$ de $1997^{5}$ y una avalancha de sentencias de la Corte Constitucional que protegen los derechos fundamentales de las mujeres, los homosexuales, los niños, los ancianos, los indígenas, las comunidades afrocolombianas, los discapacitados, los reclusos, las minorías religiosas. Entre estos derechos, han sido considerado por la Corte como violados: el derecho a la vida digna, a la igualdad, a la educación, a la integridad personal, al trabajo, a la salud, a la seguridad social, al libre desarrollo de la personalidad, a la protección especial debida a las personas de la tercera edad, a los niños, a la mujer cabeza de familia... En tales procesos legales se debe destacar el papel primordial jugado por el que podría llamarse el mayor logro, en cuanto a derechos humanos, de la constitución de 1991: la tutela. Su empleo por parte de los colombianos ha sido amplio y eficaz. Por ejemplo, entre 1992 y 1998, la Corte revisó 305 solicitudes de tutela: para el derecho a la educación (38.7 \% de las solicitudes), a la igualdad (20\%), al trabajo -presentadas principalmente por profesores- (15.1\%), libre desarrollo de la personalidad (13.4\%), debido proceso $(12.8 \%)$. Ver la Figura 4.

"Por la cual se desarrolla el artículo transitorio 55 de la Constitución Política", sobre el derecho a propiedad colectiva de las comunidades negras.

5 "Por la cual se adoptan medidas para la prevención del desplazamiento forzado; la atención, protección, consolidación y estabilización socioeconómica de los desplazados internos por la violencia en la República de Colombia". 


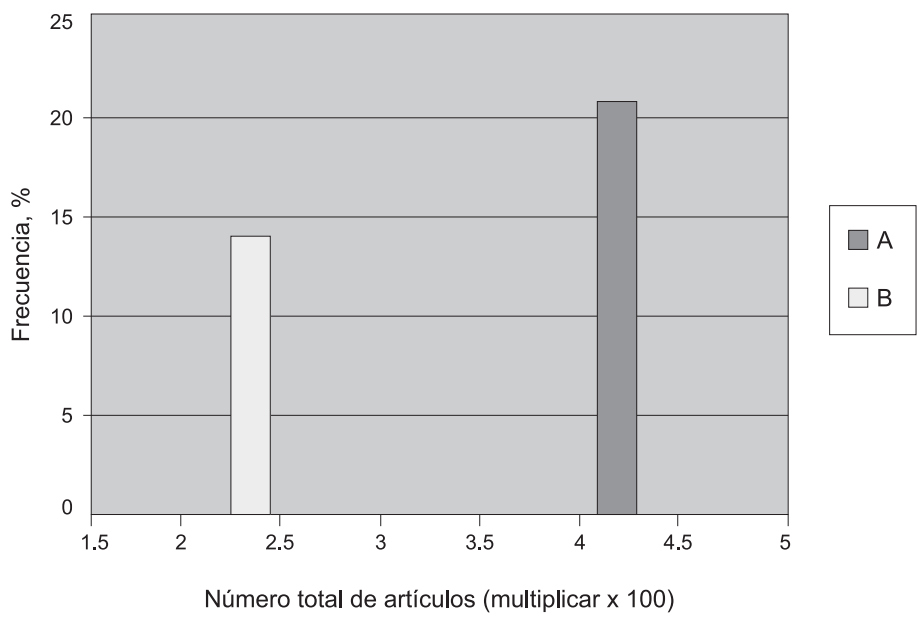

Figura 1. Ocurrencia de derechos humanos en las Constituciones del corpus (A se refiere a la de 1991; B a la de 1886).

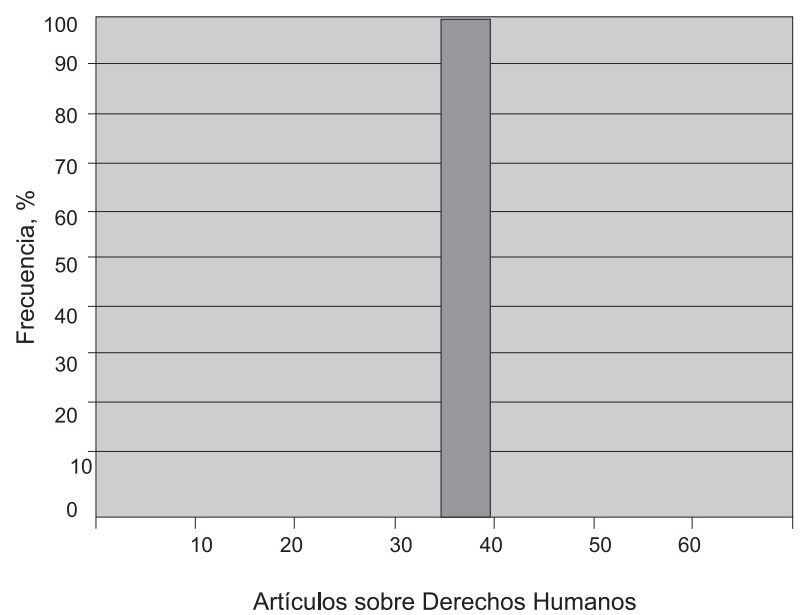

Derechos Tipo 1

Figura 2. Ocurrencia de derechos humanos, por tipo, en la Constitución de 1886. 


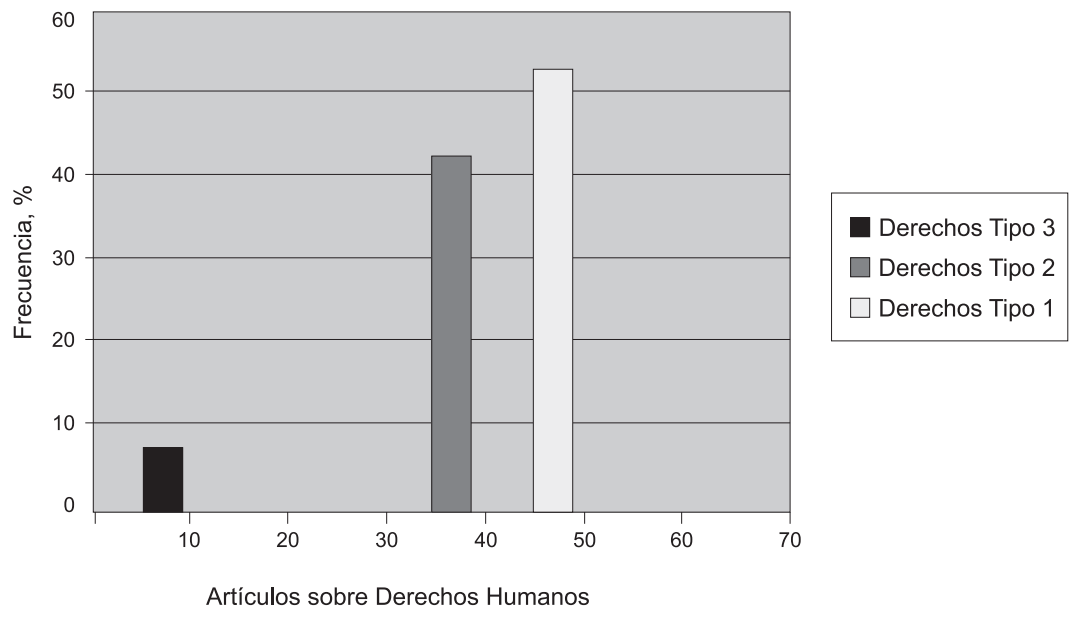

Figura 3. Ocurrencia de derechos humanos, por tipo, en la Constitución de 1991.

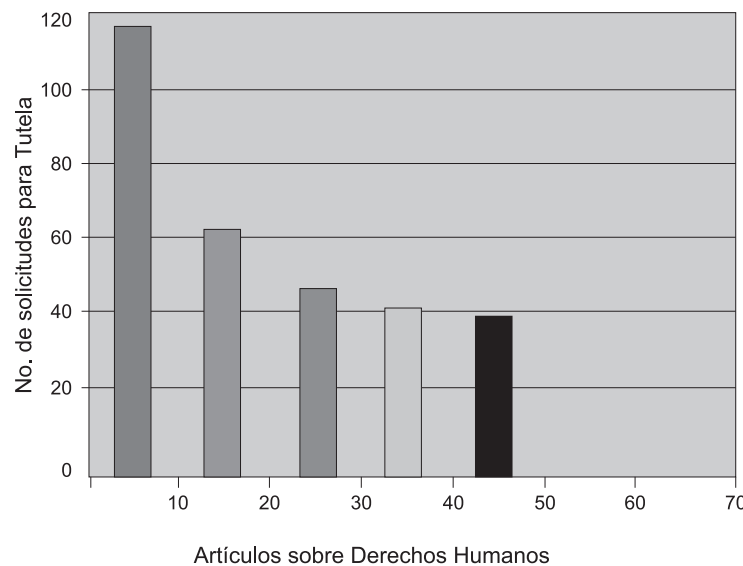

$\square$ Derecho a la Educació

$\square$ Derecho a la Igualdad

$\square$ Derecho al Trabajo

$\square$ Derecho al Libre Desarrollo de la Personalidad

Derecho al Debido Proceso

Figura 4. Derechos fundamentales comprometidos en las tutelas revisadas entre 1992 y 1998. 


\section{Ejemplos de derechos humanos, según la generación}

- Derechos humanos de primera generación. Surgen con la Revolución francesa como rebelión contra el absolutismo del monarca. Imponen al Estado el deber de respetar siempre los derechos fundamentales del ser humano:

- Derecho a la vida: conforma el preámbulo de la Constitución, esta se expidió, entre otras cosas, para asegurar a los integrantes de la nación la vida; además no siendo la Constitución una ley penal sino un código político, se prohíbe mandar o imponer la pena de muerte, por lo tanto, según el artículo 11 de la Constitución de 1991, el derecho a la vida es inviolable, no habrá pena de muerte.

- Derecho a la igualdad: la Constitución asegura a los integrantes del Estado la igualdad en la cual, en el artículo 13, todas las personas son libres e iguales ante la ley, recibirán la misma protección, trato y gozarán de los mismo derechos y libertades; el Estado protegerá a las personas que se encuentren en circunstancias de debilidad manifiesta.

- Derecho al libre desarrollo de la personalidad: todas las personas tiene derecho al libre desarrollo de su personalidad sin más limitaciones que las que impone el derecho de los demás.

- Se prohíbe la esclavitud, la servidumbre, la trata de seres humanos en todas sus formas. La libertad física o individual no es conciliable con la esclavitud, cualquiera que sea la forma que tome esta última.

- Libertad de cultos: toda persona tiene derecho a profesar libremente su religión y a difundirla de forma individual o colectiva, y a que nadie pueda molestarlo por ello, ya que sería una forma de discriminación.

- Libertad de expresión: todas las personas pueden expresar y difundir su pensamiento y opiniones por cualquier medio, aunque puede haber responsabilidad posterior por los daños o delitos causados.

- Derecho de petición: todas las personas tienen derecho de presentar de forma respetuosa una petición y esta debe obtener pronta resolución.

- Libertad de locomoción: toda persona puede desplazarse a donde quiera según su voluntad dentro del territorio.

- Derecho al trabajo: todas las personas tiene derecho a un trabajo en condiciones dignas y el Estado está en la obligación de garantizarlo.

- Libertad de profesión: todas las personas tienen la facultad de escoger la profesión u oficio y ejercer la actividad que se escoja.

- Libertad de enseñanza, aprendizaje, investigación y cátedra: es la facultad que tienen las personas para establecer institutos de enseñanza, los maestros de decir su cátedra sin restricción alguna y los padres de dar a sus hijos la enseñanza más convincente.

- Libertad: nadie puede ser molestado, ni arrestado, ni su domicilio registrado, 
sino en virtud de mandamiento escrito por autoridad competente.

- Derecho al debido proceso: nadie podrá ser juzgado sino conforme a leyes preexistentes, todas las personas son inocentes hasta que se demuestre lo contrario, y quien sea sindicado tiene derecho a la defensa durante el proceso.

- Habeas corpus: derecho concedido al detenido para pedirle al juez que verifique si su captura se llevó a cabo con garantías constitucionales o legales o de manera violenta.

- Derecho de asilo: en caso de persecución, las personas tienen derecho a refugiarse en otro país y a disfrutar de él.

- Derecho a participar en la conformación, ejercicio y control del poder político: mediante la participación en la dirección de asuntos políticos, la elección en y para cargos públicos, la conformación de partidos.

- Derechos a la intimidad, a la integridad y seguridad personal, a no ser desterrado ni sometido a confiscación de bienes -salvo "enriquecimiento ilícito- ni a prisión perpetua.

- Derechos humanos de segunda generación. Comprenden los derechos de tipo colectivo, los sociales, económicos y culturales. Surgen como resultado de la revolución industrial, por la desigualdad económica:

- Institución familiar: el Estado debe garantizar la protección integral de la familia, la pareja conformada por un hombre y una mujer tiene derecho a decidir libremente la cantidad de hijos que desea tener.

- Igualdad y protección de la mujer: la mujer no debe ser sometida a ninguna clase de discriminación, el Estado debe darle especial asistencia durante el embarazo, el parto y después de él, si estuviese desamparada y desempleada; y tiene igualdad de participación en la vida política.

- Derecho a seguridad social: como medio para garantizar la subsistencia tanto personal como familiar especialmente por falta de ingresos para la subsistencia.

- Derecho de una vivienda digna: el Estado fijará planes de vivienda de interés social y la forma de financiación.

- Derecho de asociación sindical: los empleadores y trabajadores poseen el derecho de constituir sindicatos y a través de ellos proteger y defender sus intereses.

- Derechos a la educación, la propiedad privada individual y colectiva, la propiedad intelectual, al desarrollo económico, a participar en la vida cultural, científica, literaria y artística.

- Derechos humanos de tercera generación. Surgen en nuestro tiempo como respuesta a la necesidad de cooperación entre las naciones, así como de los distintos grupos que la integran. Conforman los llamados derechos de los pueblos:

- Derecho a un ambiente sano: las personas deben gozar de un ambiente sano, 
Derecho y Realidad

diverso y conservar las áreas de importancia ecológica.

- Defensa del ambiente: queda prohibida la fabricación, importación, posesión y uso de armas químicas, biológicas y nucleares, así como la introducción al territorio de residuos nucleares y desechos tóxicos, debido a que el medio ambiente se está deteriorando y este es un mecanismo para solucionar esta degradación.

- Protección al espacio público: se debe proteger el espacio de uso común.

- Derecho a participar en el desarrollo económico y en el gozo del patrimonio de la humanidad.

- Derecho a la paz: este es un derecho y un deber de obligatorio cumplimiento, clasificado según la Declaración Universal de los Derechos Humanos, en esta tercera generación. Es un derecho colectivo y por ello busca incentivar el progreso y elevar el nivel de vida de los pueblos en el marco de la igualdad jurídica.

\section{Referencias}

Banco de la República. (s.f.). Recuperado de http://www.banrep.gov.co/blaa/ home.htm.

Cardoso, N. R. (2005, nov.). Conferencias presentadas en la Universidad Pedagógica y Tecnológica de Colombia, Doctorado en Ciencias de la Educación, Tunja.

Constitución Política de Colombia. (2006). Bogotá: Cupido.

Cruz, J. \& Díez, B. (1987). Metodología para el comentario de textos (literarios y no literarios). Madrid: Alba.

Garibello, A. (2006, 5 de feb.). Colegios se echaron a las petacas con las clases de religión: Iglesia Católica. El Tiempo, p. 1-11, c. 1-6.

Google. (s.f.). Soledad Román. Recuperado de http://www.google.com.co/ search?hl $=$ es\&q $=$ Soledad + Roman $+\& b \operatorname{tnG}=$ B \% C3\% BAsqueda\&meta.

Docencia. Udea (s.f.). Recuperado de http://docencia.udea.edu.co/derecho/ constitucion/preambulos.html Consultada 2006/02/8.

El Presidente viajará a Washington a buscar equidad en el acuerdo. Envión político de Uribe al TLC. (2006b, 9 de feb.). El Tiempo, p. 1-9, c. 1-5.

García-Pelayo \& Gross, R. (1984). Pequeño Larousse ilustrado. Buenos Aires: Larousse. 
Garrido, M. (1995). Propuestas de identidad política para los colombianos en el primer siglo de la República. En: J. Guerrero, (comp.). Iglesia, movimientos y partidos: política y violencia en la historia de Colombia. Tunja: Universidad Pedagógica y Tecnológica de Colombia.

Londoño, C. A. (1972). El perspectivismo socio-cultural latinoamericano. En: L. Sarmiento \& F. Bonell, (comp.). América Latina: 500 años después. Tunja: Universidad Pedagógica y Tecnológica de Colombia.

López-Aranguren, E. (1986). El análisis de contenido. En: M. García \& J. Ibáñez, (comp.). El análisis de la realidad social. Métodos y técnicas de investigación. Madrid: Alianza.

Piñuel, J. L. (2002). Epistemología, metodología y técnicas del análisis de contenido. Estudios de sociolingüística 3 (1), 1-42.

Pombo, M. A. \& Guerra, J. J. (1951). Constituciones de Colombia. Tomo IV. Bogotá: Ministerio de Educación Nacional.

Presidencia de la República. (1991). Constitución vigente, 1991- Constitución 1886. Bogotá: Banco de la República.

Sánchez, M. \& Noguera, C. E. (1999). La acción de tutela en la educación. Bogotá: Sociedad Colombiana de Pedagogía (SOCOLPE).

Sierra, M. A., Zapata, O. \& Sierra, A. (2007, 5, 6 y 7 de diciembre). Desplazados en Antioquia (Colombia) y algunos tratados de libre comercio en América. En: XI Congreso Internacional sobre Integración Regional, Fronteras y Globalización en el Continente Americano. Medellín.

Téllez, Y. (s.f.). Derechos humanos en las Constituciones de Colombia. Recuperado de http://correolibre.unilibrebaq.edu.co/pdhulbq/publicaciones/ publiyaninatellez2c.doc

Unión de Universidades de América Latina (editor). (1999). Historia de las universidades de América Latina. Tomo I. México: Delma.

Uribe se va a E.U. a ayudar a cerrar TLC. (2006 ${ }^{\mathrm{a}}, 9$ de feb.). El Tiempo, p. 1-1, c. 6.

Vargas, J. M. (1999). María Magdalena. Bogotá: Panamericana. 